\title{
A community-based health promotion intervention using brief negotiation techniques and a pledge on dietary intake, physical activity levels and weight outcomes: lessons learnt from an exploratory trial
}

\author{
Frances C Hillier ${ }^{1, *}$, Alan M Batterham ${ }^{2}$, Catherine A Nixon ${ }^{1}$, Alisha M Crayton ${ }^{1}$, \\ Claire L Pedley ${ }^{1}$ and Carolyn D Summerbell ${ }^{1}$ \\ 'Obesity Related Behaviours Research Group, Wolfson Research Institute, Durham University, Queen's Campus, \\ Stockton-on-Tees TS17 6BH, UK: ${ }^{2}$ Health and Social Care Institute, School of Health and Social Care, Teesside \\ University, Middlesbrough, UK
}

Submitted 22 March 2011: Accepted 27 September 2011: First published online 29 November 2011

\begin{abstract}
Objective: To assess the effectiveness of a brief face-to-face health promotion intervention which included a 'pledge' using brief negotiation techniques, compared with standard advice-giving techniques, delivered in a community setting. Design: A parallel group pre-post design using randomised matched groups. Lifestyle helpers delivered the intervention (one consultation per participant). Diet, physical activity and anthropometric measurements were collected at baseline, 6 months and 12 months. Qualitative data were also collected.

Setting: Middlesbrough (UK).

Subjects: Adults living in low socio-economic areas.

Results: Recruitment and engagement of lifestyle helpers was difficult, and initial expectations that local health authority staff working in the community and community champions would act as lifestyle helpers were not realised. As a consequence, recruitment of participants was lower than anticipated. One hundred and twenty-eight adults were recruited and the retention rate was $48 \%$ at 12 months. Barriers to participation included poor health and competing commitments. No significant differences in change in diet or physical activity behaviours, or BMI, between the intervention and control groups were observed. The control group had a significantly greater decrease in waist circumference at 12 months compared with the intervention group.

Conclusions: This exploratory trial provides important insights in terms of recruiting lifestyle helpers for community-based health promotion interventions, specifically (i) the priorities and limitations in terms of time (regardless of their general enthusiasm) for staff employed by the local health authority, and (ii) the willingness of potential community champions to serve their local community in areas where community identity and 'spirit' are seen as lacking.
\end{abstract}

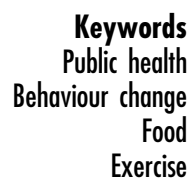

The increasing prevalence of obesity in the UK general population is a major public health concern. By 2050 we might expect $60 \%$ of men and $50 \%$ of women to be clinically obese, with obesity-related diseases costing a predicted extra $£ 45.5$ billion per year ${ }^{(1)}$. Lifestyle behavioural factors play a key role in the development of obesity as well as serious health conditions such as diabetes, coronary disease and cancer. As a result, there is a growing acknowledgment that the emphasis should shift from curative approaches to preventive strategies that target lifestyle behaviours such as diet and physical activity.

Many conventional health promotion interventions targeting unhealthy diets and low levels of physical activity continue to be based upon traditional advicegiving approaches (i.e. provision of unsolicited advice and direct persuasion). This approach can be appropriate for the management of many medical conditions, but may not be effective in public health preventive programmes $^{(2)}$. The often frustratingly small percentage of people who respond positively to advice on behaviour change, and the tendency for clinicians to label patients as 'resistant to change', can be associated with negative consequences for both parties ${ }^{(3)}$. Motivational interviewing and brief negotiation are 'directive, client-centred counselling style[s] for eliciting behaviour change by helping clients to explore and resolve ambivalence, ${ }^{,(4)}$. 
These approaches have shown encouraging results in terms of beneficial changes in physical activity, diet behaviour and/or weight outcomes in the short term (3-month followup) ${ }^{(5-7)}$ and longer term (6 months to 1 year $)^{(5,6,8-13)}$.

For community-based initiatives to be effective and sustainable, involvement of community members in the delivery of interventions is recommended ${ }^{(14,15)}$. By training key community members, skills can be developed and passed on to the wider community for many years. More successful outcomes may be seen when an intervention is delivered by a member of the same community, since they are more likely to be deemed 'trustworthy' by other community members with whom they have shared characteristics and similar life experiences ${ }^{(16,17)}$. Health promotion interventions delivered in community settings (compared with hospital settings) have the advantage of being more accessible for socially disadvantaged groups $^{(18)}$. Although some studies have shown some promising results, the evidence base for community-based obesity prevention interventions is currently limited and inconclusive ${ }^{(19,20)}$. The present study aimed to assess the effectiveness of a brief face-to-face health promotion intervention using brief negotiation techniques (intervention locations) compared with standard advice-giving techniques (control locations), delivered in a community setting, to promote healthy diets and levels of physical activity in adults living in low socio-economic areas of Middlesbrough (UK).

\section{Methods}

The study followed a parallel group pre-post design using randomised matched groups. The six public health localities (PHL) within the local health authority of Middlesbrough were included in the study. Median Index of Multiple Deprivation (IMD) scores (a single deprivation score, which combines a number of economic and social indicators, given to each small area in England) were calculated for each of the six PHL. The six PHL were grouped into each possible pair combination and a median IMD score was calculated for each. To ensure that the intervention and control sites were matched in terms of deprivation, the two pairs of PHL with the most similar median IMD score were randomly assigned to either the intervention or control group using a coin toss. The PHL in the remaining pair were assigned as pilot sites and were not included in the main study.

A key component of the health promotion intervention was a community challenge (a pledge) to improve elements of dietary intake and physical activity habits over a 1-year period. All participants were asked to make two specific pledges (one related to food and one related to physical activity) from three general themes: decrease dietary fat intake; increase fruit and vegetable intake; increase moderate- to vigorous-intensity physical activity levels.
The literature on health promotion interventions targeted at individuals who live in low socio-economic areas suggests relatively poor participation rates ${ }^{(21)}$. Specifically, this literature suggests that individuals in these areas place more value on information which is directed to the whole population, rather than just them. Consequently, an additional component was built into the design of the present study; a population Internet-based version of the intervention called 'Get a Better Life' which was targeted at all those living in Middlesbrough and surrounding areas, and was managed by the local newspaper called The Evening Gazette (FC Hillier, AM Batterham, CA Nixon et al., unpublished results).

\section{Theoretical underpinning}

The study was underpinned by two psychological models of health behaviour change: the Theory of Planned Behaviour (TPB) ${ }^{(22)}$ and Social Cognitive Theory (SCT) ${ }^{(23)}$. Conceptually, these theoretical models overlap considerably, as they both assume that behaviour change is 'goal directed' and moderated by a person's beliefs, perceptions and expectations about health behaviour in different social and environmental contexts. Several individual intervention strategies with evidence of effectiveness were incorporated into each brief intervention (control and intervention localities; Fig. 1). It was hypothesised that if an individual makes a pledge, they have displayed their behavioural intention to change their behaviour. According to the TPB, the only other variable that directly influences behaviour change is perceived behavioural control. The intervention using brief negotiation techniques (intervention localities) incorporates strategies that aim to increase perceived behavioural control by increasing the individual's self-efficacy for making behaviour changes.

\section{Lifestyle belpers}

Lifestyle helpers were recruited to deliver the intervention. Potential lifestyle helpers employed by the local health authority were invited to participate in the study as a lifestyle helper by an invitation letter or email from their respective line managers. Also, a number of local community and voluntary organisations were contacted and asked to invite their members (both paid and unpaid) to act as community champions. Lifestyle helpers attended a half-day training session: either an intervention or a control session, depending on the location in which that individual worked. The response to invitations was lower than anticipated (the target was to train forty lifestyle helpers); fifteen local health authority employees and ten community champions (one school teacher, five community workers and four volunteers) attended the training sessions.

The lifestyle helpers ( $n$ 25) were trained in the process of recruiting participants (consent procedure, making pledges, contract signing) with either additional training on motivational interviewing/brief negotiation techniques (intervention group) or no additional training (control group). 


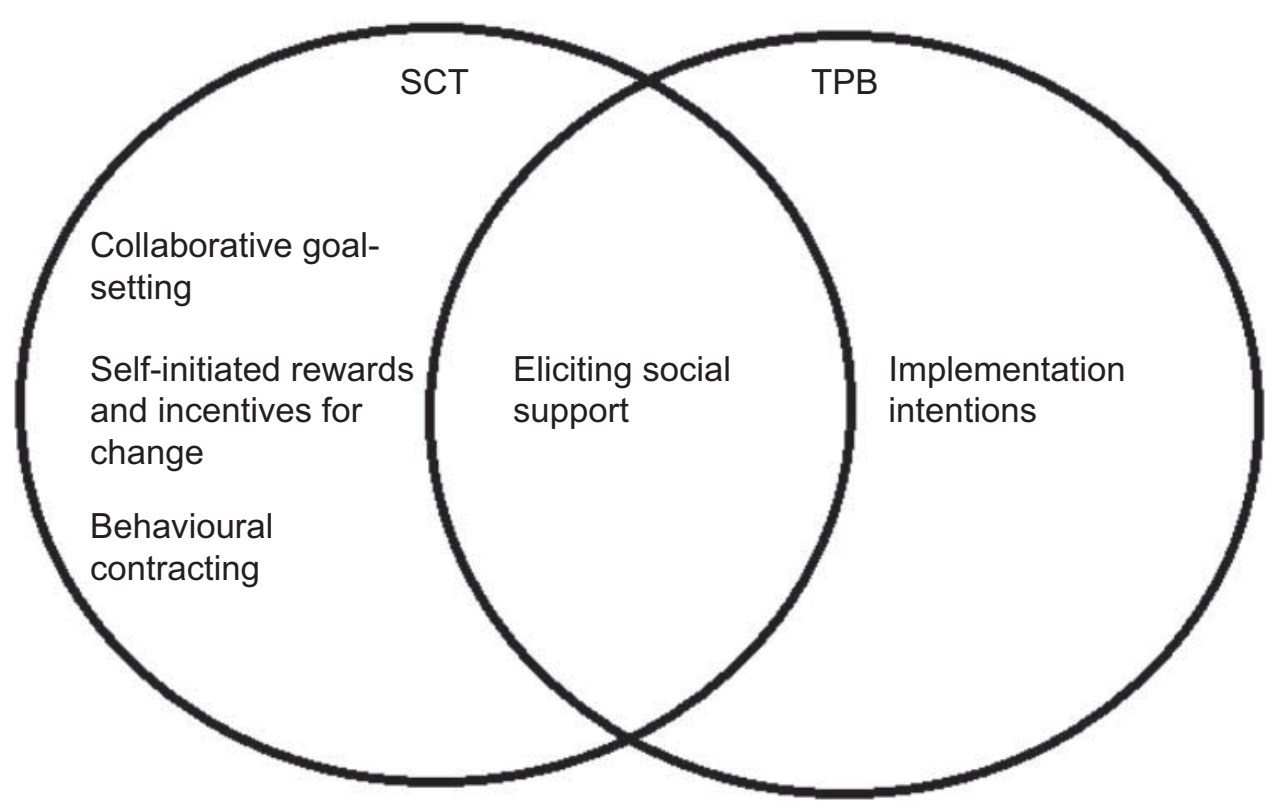

Fig. 1 Individual intervention strategies, underpinned by Social Cognitive Theory (SCT) and/or the Theory of Planned Behaviour (TPB), incorporated into each brief intervention (intervention and control)

The intervention training sessions covered techniques such as reflective listening; understanding client's motivation; resisting the righting reflex; exploring readiness to behaviour change as a tool for change talk; and exploring ambivalence. Of the twenty-five individuals trained, none managed to successfully recruit participants to the study over the first two-month period allocated for participant recruitment, and withdrew from the study. The most common reason for withdrawing was reported to be competing workloads, particularly for those employed by the local health authority.

Consequently, the recruitment strategy for the recruitment of lifestyle helpers was extended to undergraduate students of Teesside University studying health-related courses. Four students were recruited and randomised into either the control or intervention group, received the appropriate lifestyle helper training, and went on to successfully recruit participants and act as lifestyle helpers.

\section{Participants}

The original plan (before the recruitment strategy for lifestyle helpers was extended to students) was for lifestyle helpers to recruit participants in an opportunistic manner, in familiar contexts (such as health and social care initiatives targeting low-income groups, e.g. Sure Start and Healthy Living Centres; local authority community centres; participants' homes) after the primary reason for contact had been concluded. The initial intention was that the participant would then be contacted by the research team so that a baseline data collection session could be arranged.

In reality, participants were recruited to the study by members of the research team during May and October
2008, via schools (parents), workplaces, community shows and events, shopping centres, community centres, shop mobility, newspaper articles and a health event held at Teesside University. Participants were allocated to either the intervention or control group depending on the area in which they lived (or worked if recruited from a workplace). Consultations with (a student) lifestyle helper were arranged by the research team. The majority of the consultations took place in the 'Life Store' (a health service 'drop in' centre located in Middlesbrough town centre) but some also took place in participants' homes, at Teesside University or at local community centres/venues. After the consultation with the lifestyle helper, baseline data were collected by a member of the research team. Intervention consultations took approximately $30-45 \mathrm{~min}$ to deliver and control consultations approximately $15-30 \mathrm{~min}$.

In July 2008 the recruitment area was expanded to include Stockton-on-Tees and Redcar and Cleveland local health authorities (each containing four PHL). As for Middlesbrough, median IMD scores were calculated for each possible pairing of PHL within each local health authority. The two PHL pairs with the most similar median IMD scores were randomly assigned to either the control or intervention group using a coin toss; therefore, two additional PHL from Stockton-on-Tees and two additional PHL from Cleveland were assigned to both the intervention and control groups.

\section{Measures}

Outcomes were measured at baseline and at 6 months and 12 months. Baseline demographic data on age, gender, employment status and education were collected. A novel computer-based assessment tool (the Synchronised 
Nutrition and Activity Program for Adults; SNAPA ${ }^{\mathrm{TM}}$ ) was used to collect data on dietary and physical activity behaviours. SNAPA ${ }^{\mathrm{TM}}$ is a computerised previous day recall program and is described in more detail, along with results of evaluation work, elsewhere ${ }^{(24)}$. Participants completed SNAPA $^{\mathrm{TM}}$ with the assistance of a researcher at the consultation and follow-up data collection sessions. Diet and physical activity data for a second day at each time point were collected and input into SNAPA ${ }^{\mathrm{TM}}$ via telephone. The primary outcomes were: percentage of food energy from fat (\%fat); number of portions of fruit and vegetables (FV); and minutes of moderate- to vigorous-intensity physical activity (MVPA). Height (m), weight $(\mathrm{kg})$ and waist circumference $(\mathrm{cm})$ were measured by researchers accredited to Level 1 of the International Society for the Advancement of Kinanthropometry (ISAK; inter-tester technical error of measurement $\leq 2 \%$ ) using appropriate guidelines ${ }^{(25)}$.

The pledge data collected during the consultation provided useful information on the types of behaviours that were targeted by the participants. All participants who signed up to the campaign (including dropouts) were sent a feedback questionnaire after the 12 months' data collection was completed. Participants were also invited to take part in a semi-structured interview to explore participant's experiences (CA Nixon, FC Hillier, CD Summerbell et al., unpublished results).

\section{Data analysis}

Analysis was carried out using mean values of the diet and physical activity outcomes from the two days collected. A screening criterion was applied to the physical activity data to remove unfeasible data before analysis. Over-reporters were defined as MVPA $>480 \mathrm{~min} / \mathrm{d}$ (the approximate time, at the minimum threshold for MVPA of three metabolic equivalents (MET), to achieve a maximum sustainable physical activity level of $2 \cdot 5^{(26)}$ ).

Data were analysed using an analysis of covariance (ANCOVA) model, with the baseline scores as covariate to control for potential imbalances between control and intervention arms at baseline. The primary comparisons were the difference in the change in \%fat, FV and MVPA between the intervention and control at 12 months (given by the coefficient $b$, below), although the 6-month outcomes were also explored. Using $\mathrm{FV}$ as an example:

$$
\begin{aligned}
\mathrm{FV}(12 \text { months })= & a+b \times \text { group }(\text { intervention, control }) \\
& +c \times \text { baseline FV. }
\end{aligned}
$$

This model adjusts for baseline imbalance and provides the between-group difference in the change in FV from baseline to follow-up. Given the substantial proportion of zero values and oddly shaped distributions, confidence intervals were constructed via a criterion non-parametric bootstrapping method ${ }^{(27)}$. On each of 10000 resampling runs, $n$ cases (given by the sample size) were randomly selected with replacement from within the original data (maintaining case correspondence). The $90 \%$ confidence interval for the population mean difference was then derived by taking the 5th and 95th percentile of the 10000 stored differences (Resampling Stats version 4.0.7; Resampling Stats Inc., Arlington, VA, USA). The ANCOVA method described above was applied to the BMI and weight outcomes, but with confidence intervals constructed via standard parametric analytical formulas.

\section{Sample size estimation}

The sample size estimation was matched explicitly to the intended analysis. A correlation between baseline measures of $0 \cdot 7$, between follow-up measures of 0.7 and between baseline and follow-up of 0.5 was assumed (realistic, conservative estimates for self-report tools based on unpublished observations). For $90 \%$ power to detect the intervention effect of half a portion of $\mathrm{FV}$ $(2 P=0 \cdot 05)$, the STATA 'method ANCOVA' produced a required sample size of 189 participants in each group (based on an estimated population standard deviation of 2.01 portions taken from the National Diet and Nutrition Survey $\left.{ }^{(28)}\right)$. An allowance for attrition of $30 \%$ inflated the target number to 270 participants in each arm.

It was recognised that in this study individuals are not the unit of randomisation. Rather, six PHL were randomly allocated to each arm. Hence, theoretically there is some element of clustering. This could not be accounted for post-study by multilevel modelling/random effects type procedures as there were insufficient numbers of clusters in each arm to estimate the variances robustly. Data were therefore analysed at the individual level. A negligible intra-class correlation (ICC) for this pragmatic community trial was assumed and hence no allowance was made for any design effect of clustering; ICC for the changes from baseline to 6 months, for example, in the current study were 0.00000 (truncated at zero) for FV, 0.05 for $\%$ fat and $0 \cdot 00000$ (truncated at zero) for MVPA.

\section{Results}

\section{Recruitment of participants}

A total of 128 people (sixty-nine intervention, fifty-nine control) were recruited initially, falling well short of the target sample size. Retention rates were similar in both groups and at each follow-up data collection time point (between $47 \%$ and 49\%). Participants who had been unable to attend a 6-month data collection session for whatever reason (e.g. illness, lack of time, competing commitments) were invited to attend the 12-month data collection session, unless they had informed the research team they no longer wished to take part in the study. Reasons for dropping out of the study included illness of participant or a family member ( $n 11)$, too busy with other commitments $(n 6)$ and moving away from the area $(n 2)$. 
Table 1 Characteristics of participants at baseline and follow-up: adults living in low socio-economic areas, Middlesbrough, UK

\begin{tabular}{|c|c|c|c|c|c|c|c|c|c|c|c|c|}
\hline & \multicolumn{4}{|c|}{ Baseline } & \multicolumn{4}{|c|}{6 months } & \multicolumn{4}{|c|}{12 months } \\
\hline & \multicolumn{2}{|c|}{ Control ( $n$ 59) } & \multicolumn{2}{|c|}{ Intervention ( $n$ 69) } & \multicolumn{2}{|c|}{ Control (n 28) } & \multicolumn{2}{|c|}{ Intervention ( $n$ 32) } & \multicolumn{2}{|c|}{ Control (n 29) } & \multicolumn{2}{|c|}{ Intervention ( $n$ 34) } \\
\hline & Mean & Range & Mean & Range & Mean & Range & Mean & Range & Mean & Range & Mean & Range \\
\hline \multirow[t]{2}{*}{ Age (years) } & $45 \cdot 6$ & $19-79$ & $41 \cdot 7$ & $16-70$ & $43 \cdot 6$ & $19-73$ & $41 \cdot 6$ & $17-66$ & $49 \cdot 1$ & $21-73$ & $42 \cdot 8$ & $17-70$ \\
\hline & $n$ & $\%$ & $n$ & $\%$ & $n$ & $\%$ & $n$ & $\%$ & $n$ & $\%$ & $n$ & $\%$ \\
\hline \multicolumn{13}{|l|}{ Gender } \\
\hline Female & 37 & $62 \cdot 7$ & 59 & $85 \cdot 5$ & 17 & $60 \cdot 7$ & 29 & $90 \cdot 6$ & 19 & $59 \cdot 4$ & 32 & $94 \cdot 1$ \\
\hline Male & 22 & $37 \cdot 3$ & 10 & $14 \cdot 5$ & 11 & $39 \cdot 3$ & 3 & $9 \cdot 4$ & 10 & $31 \cdot 3$ & 2 & $5 \cdot 9$ \\
\hline \multicolumn{13}{|l|}{ Ethnicity } \\
\hline White & 53 & $89 \cdot 8$ & 56 & $81 \cdot 2$ & 25 & $89 \cdot 3$ & 28 & $87 \cdot 5$ & 28 & $87 \cdot 5$ & 29 & $85 \cdot 3$ \\
\hline Other* & 3 & $5 \cdot 1$ & 4 & $5 \cdot 8$ & 3 & $10 \cdot 7$ & 1 & $3 \cdot 1$ & 1 & $3 \cdot 1$ & 2 & $5 \cdot 9$ \\
\hline Not reported & 3 & $5 \cdot 1$ & 9 & $13 \cdot 0$ & - & - & 3 & $9 \cdot 4$ & 3 & $9 \cdot 4$ & 3 & $8 \cdot 8$ \\
\hline \multicolumn{13}{|l|}{ Education } \\
\hline University degree, postgraduate degree & 5 & $8 \cdot 5$ & 14 & $20 \cdot 3$ & 4 & $14 \cdot 3$ & 6 & $18 \cdot 8$ & 5 & $17 \cdot 2$ & 9 & $26 \cdot 5$ \\
\hline Further education, A/AS level, Diploma & 26 & $44 \cdot 0$ & 23 & $33 \cdot 3$ & 14 & $50 \cdot 0$ & 10 & $31 \cdot 2$ & 14 & $48 \cdot 3$ & 9 & $26 \cdot 5$ \\
\hline Secondary school, GCSE & 22 & $37 \cdot 3$ & 21 & $30 \cdot 4$ & 10 & $35 \cdot 7$ & 12 & $37 \cdot 5$ & 10 & $34 \cdot 5$ & 12 & $35 \cdot 3$ \\
\hline Not reported & 6 & $10 \cdot 2$ & 11 & $16 \cdot 0$ & - & - & 4 & $12 \cdot 5$ & - & - & 4 & $11 \cdot 7$ \\
\hline \multicolumn{13}{|l|}{ Employment } \\
\hline Employed full time & 22 & $37 \cdot 3$ & 26 & $37 \cdot 7$ & 14 & $50 \cdot 0$ & 10 & $31 \cdot 3$ & 14 & $43 \cdot 8$ & 14 & $41 \cdot 2$ \\
\hline Employed part time & 4 & $6 \cdot 8$ & 10 & $14 \cdot 5$ & 5 & $17 \cdot 9$ & 6 & $18 \cdot 8$ & 3 & $9 \cdot 4$ & 4 & $11 \cdot 8$ \\
\hline Full-time education & 1 & $1 \cdot 7$ & 4 & $5 \cdot 8$ & 1 & $3 \cdot 6$ & 1 & $3 \cdot 1$ & - & - & 1 & $2 \cdot 9$ \\
\hline Retired & 12 & $20 \cdot 3$ & 6 & $10 \cdot 2$ & 4 & $14 \cdot 3$ & 2 & $6 \cdot 3$ & 8 & $25 \cdot 0$ & 3 & $8 \cdot 8$ \\
\hline Unemployed & 10 & $16 \cdot 9$ & 5 & $7 \cdot 2$ & 3 & $10 \cdot 7$ & 4 & $12 \cdot 5$ & 2 & $6 \cdot 3$ & 2 & $5 \cdot 9$ \\
\hline Voluntary worker & 4 & $6 \cdot 8$ & - & - & 1 & $3 \cdot 6$ & - & - & 2 & $6 \cdot 3$ & - & - \\
\hline Homemaker & 2 & $3 \cdot 4$ & 6 & $8 \cdot 7$ & - & - & 4 & $12 \cdot 5$ & - & - & 5 & $14 \cdot 7$ \\
\hline Self-employed & - & - & 3 & $4 \cdot 3$ & - & - & 2 & $6 \cdot 3$ & - & - & 2 & $5 \cdot 9$ \\
\hline Full-time carer & 1 & $1 \cdot 7$ & - & - & - & - & - & & - & - & - & - \\
\hline Not reported & 3 & $5 \cdot 1$ & 9 & $13 \cdot 0$ & - & - & 3 & $9 \cdot 4$ & - & - & 3 & $8 \cdot 8$ \\
\hline
\end{tabular}

*Black Caribbean, Indian, Pakistani, Filipino, Danish/British. 
Table 2 Categories of pledges made by participants $\left(n 128^{*}\right)$ : adults living in low socio-economic areas, Middlesbrough, UK

\begin{tabular}{lrr}
\hline Pledge & $n$ & $\%$ \\
\hline Diet pledges & & \\
Increase fruit \& vegetable intake & 55 & $43 \cdot 0$ \\
Reduce fat & 23 & $18 \cdot 0$ \\
Reduce unhealthy snacks & 34 & $26 \cdot 6$ \\
Reduce salt & 2 & $1 \cdot 6$ \\
Reduce sugar & 2 & $1 \cdot 6$ \\
Eat healthy snacks & 2 & $1 \cdot 6$ \\
Reduce takeaway/processed foods & 9 & $7 \cdot 0$ \\
Reduce alcohol & 2 & $1 \cdot 6$ \\
Change cooking method (e.g. grill instead of fry) & 5 & $3 \cdot 9$ \\
Eat healthy/balanced meals & 15 & $11 \cdot 7$ \\
Eat smaller portions & 5 & $3 \cdot 9$ \\
Replace high-fat/sugary foods with healthier & 12 & $9 \cdot 4$ \\
alternatives & & \\
Physical activity pledges & & \\
Exercise once/week & 4 & $3 \cdot 1$ \\
Exercise twice/week & 3 & $2 \cdot 3$ \\
Exercise three or more times/week & 11 & $8 \cdot 6$ \\
Walking & 56 & $43 \cdot 8$ \\
Cycling/use exercise bike & 5 & $3 \cdot 9$ \\
Gym/keep fit class & 25 & $19 \cdot 5$ \\
Jogging/running & 6 & $4 \cdot 7$ \\
Swimming/aqua aerobics & 10 & $7 \cdot 8$ \\
Wii Fit/other training equipment & 14 & $10 \cdot 9$ \\
Maintain current physical activity levels & 20 & $15 \cdot 6$ \\
\hline
\end{tabular}

*Total frequencies for each type of pledges exceed 128, as some participants targeted more than one behaviour within one/each pledge.

The remaining dropouts were for reasons unknown ( $n$ 24) or being unable to contact at follow-up time points ( $n 22$ ).

The sample characteristics are reported in Table 1 . The mean age of participants in each group ranged from $41 \cdot 6$ to $49 \cdot 1$ years of age throughout the data collection periods. The control group contained a greater proportion of men than the intervention, consistently over the year. This was probably as a result of a number of male participants $(n 9)$ who were recruited through the workplace Corus Steel, located in one of the control areas.

\section{Pledges and reasons for taking part}

Table 2 displays a breakdown of the behaviours that the participants' pledges targeted. Although encouraged to pledge against either fat intake or fruit and vegetable intake, some participants, as an addition, included other behaviours (e.g. reduce alcohol, salt or sugar intake, smaller portion sizes) in their diet pledge. The main goal of taking part in the health promotion intervention, identified in the feedback questionnaires, was to lose weight. Other goals identified were improving fitness, achieving a healthier lifestyle and achieving a healthier diet.

\section{Diet, physical activity and antbropometric outcomes}

Most physical activity and diet data were collected for a weekday (Monday to Friday): a mean of $87 \%$ and $91 \%$ in the intervention and control groups, respectively. Four participants (all in the control group) reported more than
480 min of MVPA on one of the two days at 6 months; therefore, these days of data were removed from the analysis, and only one day of physical activity data were used for these participants. Table 3 shows all outcomes at each data collection time point (baseline $v$. 6 months; baseline $v .12$ months). Daily \%fat ranged between mean values of $32 \cdot 1 \%$ and $35.0 \%$ in the control group, and between $29 \cdot 7 \%$ and $32.7 \%$ in the intervention group, over the period of the study. Mean FV intake ranged between 3.2 and 3.9 portions/d in the control group, and between $3 \cdot 0$ and $4 \cdot 0$ portions/ $\mathrm{d}$ in the intervention group. For minutes of MVPA daily, data were skewed towards zero; therefore, it may be more appropriate to consider the median value when interpreting these data. Median values between zero and $30 \mathrm{~min}$ MVPA/d were observed in the control group over the duration of the study, and between zero and $21 \mathrm{~min} \mathrm{MVPA} / \mathrm{d}$ was observed in the intervention group. ANCOVA revealed no significant intervention effect on any of the diet and physical activity behaviour outcomes.

Weight and BMI remained fairly consistent with baseline at 6 months, with slight decreases in weight and BMI at 12 months in both groups. There were no significant differences in the change in weight or BMI between both groups at either time point. An increase in waist circumference was observed in the intervention group at 12 months, whereas small decreases were observed in the control group at both 6 and 12 months. This resulted in an overall significant increase in waist circumference as a result of the intervention, relative to changes in the control group.

\section{Experience of taking part}

Thirty-one participants completed the feedback questionnaire. Responses to the feedback questionnaire were anonymous; therefore, we are unable to identify which group the participants were assigned to. The majority of responders $(96 \cdot 8 \%)$ gave high rating scores for the consultation session with the lifestyle helper. A number of respondents rated family, friends and/or colleagues as being of particular help in working towards their pledges (48.1\%). The most common barriers to making healthful changes and working towards pledges identified in the feedback questionnaire responses were: physical barriers, e.g. health problems (31\%); psychological barriers, e.g. lack of motivation (27.6\%); and lack of support (20.7\%). Data from the semi-structured interviews supported findings from the feedback questionnaire (CA Nixon, FC Hillier, CD Summerbell et al., unpublished results).

\section{Discussion}

The original plan was to recruit participants through the trained lifestyle helpers who had existing roles in the community. However, twenty-five out of the twenty-nine 
Table 3 Diet and physical activity outcomes, and weight, BMI and waist circumference, at baseline and 6 months and baseline and 12 months, and mean effect of the intervention (intervention minus control) for outcomes (adjusted for baseline in an analysis of covariance model): adults living in low socio-economic areas, Middlesbrough, UK

\begin{tabular}{|c|c|c|c|c|c|c|c|c|c|c|c|c|c|c|c|c|c|c|}
\hline & \multicolumn{8}{|c|}{ Control } & \multicolumn{8}{|c|}{ Intervention } & \multirow{3}{*}{$\begin{array}{l}\text { Mean } \\
\text { change }\end{array}$} & \multirow{3}{*}{$\begin{array}{c}\text { Bootstrapped } \\
90 \% \mathrm{Cl}\end{array}$} \\
\hline & \multicolumn{4}{|c|}{ Baseline } & \multicolumn{4}{|c|}{6 months } & \multicolumn{4}{|c|}{ Baseline } & \multicolumn{4}{|c|}{6 months } & & \\
\hline & Mean & SD & Median & Range & Mean & SD & Median & Range & Mean & SD & Median & Range & Mean & SD & Median & Range & & \\
\hline \multicolumn{19}{|c|}{$\begin{array}{l}\text { Diet and physical } \\
\text { activity outcomes* }\end{array}$} \\
\hline \%fat & $34 \cdot 4$ & 8.9 & $34 \cdot 2$ & $17 \cdot 8-52 \cdot 7$ & $35 \cdot 0$ & $8 \cdot 1$ & $35 \cdot 4$ & $18 \cdot 8-54 \cdot 4$ & $32 \cdot 7$ & $7 \cdot 9$ & $34 \cdot 9$ & $17 \cdot 7-51 \cdot 7$ & $32 \cdot 2$ & $8 \cdot 3$ & $32 \cdot 6$ & $8 \cdot 6-46 \cdot 2$ & $-2 \cdot 6$ & $-6 \cdot 2,1 \cdot 0$ \\
\hline FV portions & 3.9 & $3 \cdot 4$ & $3 \cdot 1$ & $0 \cdot 0-12 \cdot 0$ & $3 \cdot 2$ & $2 \cdot 3$ & $3 \cdot 0$ & $0 \cdot 0-9 \cdot 6$ & $3 \cdot 0$ & $2 \cdot 1$ & $3 \cdot 0$ & $0 \cdot 0-7 \cdot 0$ & 3.3 & $2 \cdot 6$ & $2 \cdot 8$ & $0 \cdot 0-9 \cdot 0$ & 0.5 & $-0.5,1 \cdot 3$ \\
\hline Min MVPA/d & 36 & 39 & 30 & $0-135$ & $36 \cdot 3$ & 69.6 & 0 & $0-233$ & 47 & 75 & 18 & $0-330$ & 31 & 62 & 0 & $0-240$ & -4 & $-37,25$ \\
\hline \multicolumn{19}{|l|}{$\begin{array}{l}\text { Anthropometric } \\
\text { outcomest }\end{array}$} \\
\hline Weight (kg) & $80 \cdot 0$ & $18 \cdot 1$ & & & $80 \cdot 0$ & $18 \cdot 4$ & & & $80 \cdot 2$ & $15 \cdot 7$ & & & $79 \cdot 5$ & $16 \cdot 4$ & & & -0.7 & $-2 \cdot 0,0 \cdot 6$ \\
\hline $\mathrm{BMI}\left(\mathrm{kg} / \mathrm{m}^{2}\right)$ & $27 \cdot 9$ & $5 \cdot 3$ & & & $27 \cdot 9$ & $5 \cdot 4$ & & & $29 \cdot 9$ & 4.8 & & & $29 \cdot 6$ & 4.9 & & & -0.3 & $-0.8,0.2$ \\
\hline \multirow[t]{3}{*}{ WC $(\mathrm{cm})$} & $94 \cdot 7$ & $13 \cdot 8$ & & & $93 \cdot 8$ & 14.9 & & & $96 \cdot 1$ & $12 \cdot 0$ & & & $98 \cdot 2$ & $12 \cdot 5$ & & & $3 \cdot 1$ & $1 \cdot 2,5 \cdot 0$ \\
\hline & \multicolumn{4}{|c|}{ Baseline } & \multicolumn{4}{|c|}{12 months } & \multicolumn{4}{|c|}{ Baseline } & \multicolumn{4}{|c|}{12 months } & & \\
\hline & Mean & SD & Median & Range & Mean & SD & Median & Range & Mean & SD & Median & Range & Mean & SD & Median & Range & & \\
\hline \multicolumn{19}{|c|}{$\begin{array}{l}\text { Diet and physical } \\
\text { activity outcomesł }\end{array}$} \\
\hline \%fat & $34 \cdot 3$ & $7 \cdot 7$ & $34 \cdot 9$ & $18 \cdot 2-48 \cdot 8$ & $32 \cdot 1$ & $7 \cdot 9$ & $32 \cdot 7$ & $9 \cdot 4-46 \cdot 8$ & $32 \cdot 1$ & $8 \cdot 9$ & $34 \cdot 7$ & $7 \cdot 7-49 \cdot 4$ & $29 \cdot 7$ & $9 \cdot 8$ & 28.5 & $7 \cdot 9-12 \cdot 0$ & $-1 \cdot 6$ & $-5 \cdot 1,1 \cdot 7$ \\
\hline FV portions & 3.7 & $3 \cdot 3$ & 2.5 & $0.0-12 \cdot 0$ & 3.6 & $2 \cdot 8$ & $2 \cdot 6$ & $0.6-13 \cdot 0$ & $3 \cdot 2$ & 2.6 & 3.0 & $0.0-12.0$ & 4.0 & $2 \cdot 8$ & 3.6 & $0.0-13.0$ & 0.6 & $-0.4,1.5$ \\
\hline Min MVPA/d & 24 & 36 & 0 & $0-135$ & 50 & 106 & 0 & $0-420$ & 47 & 71 & 21 & $0-330$ & 38 & 62 & 15 & $0-300$ & -12 & $-50,23$ \\
\hline \multicolumn{19}{|l|}{$\begin{array}{l}\text { Anthropometric } \\
\text { outcomes } \S\end{array}$} \\
\hline Weight (kg) & $76 \cdot 2$ & $16 \cdot 4$ & & & $75 \cdot 3$ & $16 \cdot 1$ & & & $79 \cdot 4$ & $16 \cdot 3$ & & & $75 \cdot 5$ & $21 \cdot 1$ & & & 0.2 & $-1 \cdot 5,1 \cdot 8$ \\
\hline BMI $\left(\mathrm{kg} / \mathrm{m}^{2}\right)$ & $27 \cdot 7$ & 4.8 & & & $27 \cdot 4$ & 4.8 & & & $29 \cdot 9$ & $5 \cdot 8$ & & & 28.5 & $7 \cdot 8$ & & & 0.1 & $-0.6,0.7$ \\
\hline WC $(\mathrm{cm})$ & $93 \cdot 2$ & $12 \cdot 4$ & & & 92.5 & 13.0 & & & $95 \cdot 3$ & $12 \cdot 1$ & & & 95.0 & $22 \cdot 0$ & & & $3 \cdot 6$ & $0 \cdot 8,6 \cdot 3$ \\
\hline
\end{tabular}

\%fat, percentage of food energy from fat; FV, fruits and vegetables; MVPA, moderate- to vigorous-intensity physical activity; WC, waist circumference.

*Control $n 28$, intervention $n 32$.

tControl $n 26$, intervention $n 30$.

‡Control $n 29$, intervention $n 34$.

§Control $n 24$, intervention $n 31$ 
individuals trained did not fulfil their role as a lifestyle helper. Only the four student volunteers delivered consultations, at appointments pre-arranged by the research team. Findings from semi-structured interviews (CA Nixon, FC Hillier, CD Summerbell et al., unpublished results) and anecdotal evidence collected through field notes suggest that those trained as lifestyle helpers found putting what was learnt into practice more difficult than anticipated. Local health authority employees reported that they were hampered by a lack of time to deliver the intervention, especially as the primary reason for visits with clients was related to their everyday roles and duties, and not the study. Although essential, procedures to ensure informed consent are time consuming and can seem complex, and may have proved a step too far for an opportunistic intervention. Time constraints and difficulty with consent procedures have been previously identified as barriers for participation in research by health professionals ${ }^{(29)}$. The organisational structure of the public health workforce in England continues to change, and employees reported that meeting the needs of these changes was challenging and their priority; and as such the delivery of the intervention was sidelined.

A number of local health authority employees, although not able to commit to a lifestyle helper role, were enthusiastic about the study and extremely helpful in signposting the research team to other individuals and groups in the community. These employees have a wealth of knowledge, acquired over time, and involving these individuals as a gateway into communities may be a more successful approach. On reflection, too much reliance was placed on local health authority employees to act as lifestyle helpers in the present study. Community champions were recruited through contacts with existing community networks and organisations; however, different strategies may have been more effective. Examples from other studies where community members have been recruited to deliver interventions include direct advertising in local media ${ }^{(30)}$ and employing workers on a part-time basis ${ }^{(10)}$. Using known community members as community champions is considered a more effective approach to community-based health promotion ${ }^{(16,17)}$; therefore, using student volunteers, not previously known by the participants, might have affected recruitment and retention rates in the study.

The low recruitment rate of lifestyle helpers led to difficulties recruiting the required number of participants. An estimate of recruitment rate was taken using researcher field notes during the active canvassing sessions at shopping centres, community events and a health event held at Teesside University. Approximately one in twenty of those who were approached was recruited to the study and completed a consultation with a lifestyle helper. In terms of participant recruitment to community-based health promotion interventions to achieve the target sample size, we recommend using a predicted response rate of $<5 \%$ as a guideline for 'hard to reach' adults and a varied range of recruitment strategies which involve researchers attending community events in the evenings and at weekends. Recruiting participants through community groups, schools and workplaces was relatively successful. A main contact was identified within the group or organisation who took on a peer leader' role and assisted in the arrangement of group consultation sessions.

The lack of effect of a brief intervention on diet and physical activity behaviours may be the result of the intervention being of insufficient intensity to promote a change in behaviour. In the majority of previous studies using motivational interviewing techniques, more than one session was delivered ${ }^{(31)}$, whereas only one session was used in the present study. However, in one childhood obesity prevention study where sessions were delivered to parents, decreases in BMI were observed in both the group receiving a minimal intervention (one motivational interviewing session) and the group receiving an intensive intervention (two motivational interviewing sessions), with no significant differences between the groups ${ }^{(32)}$. The intervention lifestyle helpers were given the Behaviour Change Counselling Index (BECCI) and were encouraged to use this to self-monitor their performance when delivering the consultations. However, since no formal fidelity measures were taken, treatment integrity of the intervention consultations over the course of the study is unknown.

The effect of the intervention on waist circumference in the present study is unexpected (decreased in the control group compared with the intervention group). This finding is unlikely to be a result of measurement error; all researchers were ISAK-accredited Level 1 anthropometrists trained in waist circumference measurement.

A lack of intervention effect on diet and physical activity behaviour may also be a result of limitations in the data collection method. SNAPA ${ }^{\mathrm{TM}}$ showed reasonable correlations with standard methods of dietary and physical activity assessment ${ }^{(24)}$; however, we recognise the limitations of self-report methods in the assessment of diet and physical activity, mainly due to the increased error (imprecision) of self-report methods. The original sample size estimation took into account this inflated measurement error and would have ensured sufficient power to detect the targeted differences if the estimated numbers had been recruited and retained.

\section{Conclusions}

The present exploratory study provides valuable information on the processes involved in implementing a community-based health promotion intervention. In terms of recruiting lifestyle helpers for community-based health promotion interventions it is important to consider the 
priorities, and limitations in terms of time (regardless of their general enthusiasm), for staff employed by the local health authority. It is also important not to overestimate the willingness of potential community champions to serve their local community in areas where community identity and 'spirit' are seen as lacking.

In terms of recruiting participants to community-based health promotion interventions, we suggest that a varied and innovative range of recruitment strategies is employed which involve researchers attending community events in the evenings and at weekends. The lessons learnt from the present study may be useful for the development and implementation of future community-based obesity prevention interventions.

\section{Acknowledgements}

The present study was part of a larger project funded by the Food Standards Agency (N14008). There are no conflicting interests to declare. F.C.H. managed the study and collected data with the assistance of C.A.N., A.M.C. and C.L.P. A.M.B. and C.D.S. advised on the development and evaluation of the study. A.M.B. and F.C.H. conducted the analysis and, with C.D.S., the interpretation. F.C.H. drafted the article, and C.D.S. and A.M.B. contributed to revised successive drafts. The authors would like to thank Rob Lyon who delivered the intervention lifestyle helper training session and the student lifestyle helpers. They would also like to acknowledge all the local health authority staff members and community champions who were involved in the study; the steering group members Professor Ashley Adamson, Professor David Hunter and Professor Margaret Thorogood; and Sean Crooks for his computer programming expertise.

\section{References}

1. Butland B, Jebb S, Kopelman P et al. (2007) Tackling Obesities: Future Choices - Project Report. London: Government Office for Science.

2. Rollnick S, Mason P \& Butler C (1999) Health Behavior Change: A Guide for Practitioners. New York: Churchill Livingstone.

3. Rollnick S (1996) Behaviour change in practice: targeting individuals. Int J Obes Relat Metab Disord 20, Suppl. 1 , S22-S26.

4. Rollnick S \& Miller WR (1995) What is motivational interviewing? Behav Cog Psychother 23, 325-334.

5. Bennett JA, Lyons KS, Winters-Stone K et al. (2007) Motivational interviewing to increase physical activity in long-term cancer survivors: a randomized controlled trial. Nurs Res 56, 18-27.

6. Hardcastle S, Taylor A, Bailey M et al. (2008) A randomised controlled trial on the effectiveness of a primary health care based counselling intervention on physical activity, diet and CHD risk factors. Patient Educ Couns 70, 31-39.

7. Perry CK, Rosenfeld AG, Bennett JA et al. (2007) Heart-toheart: promoting walking in rural women through motivational interviewing and group support. J Cardiovasc Nurs 22, 304-312.
8. Bowen D, Ehret C, Pedersen M et al. (2002) Results of an adjunct dietary intervention program in the women's health initiative. J Am Diet Assoc 102, 1631-1637.

9. Elliot DL, Goldberg L, Kuehl KS et al. (2007) The PHLAME (Promoting Healthy Lifestyles: Alternative Models' Effects) Firefighter Study: outcomes of two models of behavior change. J Occup Environ Med 49 , 204-213.

10. Greaves C, Middlebrooke A, O'Loughlin L et al. (2008) Motivational interviewing for modifying diabetes risk: a randomised controlled trial. Br J Gen Pract 58, 535-540.

11. Resnicow K, Campbell MK, Carr C et al. (2004) Body and soul: a dietary intervention conducted through AfricanAmerican churches. Am J Prev Med 27, 97-105.

12. Resnicow K, Jackson A, Wang T et al. (2001) A motivational interviewing intervention to increase fruit and vegetable intake through Black churches: results of the Eat for Life trial. Am J Public Health 91, 1686-1693.

13. Hillsdon M, Thorogood M, White I et al. (2002) Advising people to take more exercise is ineffective: a randomized controlled trial of physical activity promotion in primary care. Int J Epidemiol 31, 808-815.

14. Economos CD \& Irish-Hauser SA (2007) Community interventions: a brief overview and their application to the obesity epidemic. J Law Med Ethics 35, 131-137.

15. Israel BA, Schulz AJ, Parker EA et al. (1998) Review of community-based research: assessing partnership approaches to improve public health. Annu Rev Public Health 19, 173-202.

16. Orrell-Valente JK, Pinderhughes EE, Valente E et al. (1999) If it's offered, will they come? Influences on parents' participation in a community-based conduct problems prevention program. Am J Community Psychol 27, 753-783.

17. Cohen S \& McKay G (1984) Social support, stress, and the buffering hypothesis, a theoretical analysis. In Handbook of Psychology and Health, pp. 253-267 [A Baum, SE Taylor and JE Singer, editors]. Hillsdale, NJ: Lawrence Erlbaum Associates.

18. Poland B, Green L \& Rootman I (2000) Settings for Health Promotion: Linking Theory and Practice. Thousand Oaks/ Newbury Park, CA: SAGE Publications.

19. Summerbell C \& Hillier F (2010) Community interventions and initiatives to prevent obesity. In Obesity Epidemiology: From Aetiology to Public Health, pp. 395-408 [D Crawford, R Jeffery, K Ball et al., editors]. Oxford: Oxford University Press.

20. Swinburn B \& Egger G (2002) Preventive strategies against weight gain and obesity. Obes Rev 3, 289-301.

21. Michie S, Jochelson K, Markham WA et al. (2009) Low-income groups and behaviour change interventions: a review of intervention content, effectiveness and theoretical frameworks. J Epidemiol Community Health 63, 610-622.

22. Ajzen I (1991) The theory of planned behaviour. Organ Behav Hum Decis Process 50, 179-211.

23. Bandura A (1986) Social Foundations of Thought and Action: A Social Cognitive Theory. Englewood Cliffs, NJ: Prentice Hall.

24. Hillier FC, Batterham AM, Crooks S et al. (2011) The development and evaluation of a novel Internet-based computer program to assess previous-day dietary and physical activity behaviours in adults: the Synchronised Nutrition and Activity Program for Adults (SNAPA $\left.{ }^{\mathrm{TM}}\right) . B r J$ Nutr (Epublication ahead of print version).

25. National Institutes of Health, National Heart, Lung, and Blood Institute \& North American Association for the Study of Obesity (2000) The Practical Guide: Identification, Evaluation and Treatment of Overweight and Obesity in Adults. Bethesda, MD: NHLBI. 
26. Westerterp KR (2001) Limits to sustainable human metabolic rate. J Exp Biol 204, 3183-3187.

27. Efron B \& Tibshirani RJ (1993) An Introduction to the Bootstrap. New York: Chapman \& Hall.

28. Henderson L, Gregory J \& Swan G (2002) The National Diet and Nutrition Survey: Adults Aged 19 to 64 Years. vol. 1: Types and Quantities of Foods Consumed. London: TSO.

29. Ross S, Grant A, Counsell C et al. (1999) Barriers to participation in randomised controlled trials: a systematic review. J Clin Epidemiol 52, 1143-1156.
30. Watt R, McGlone P, Russell J et al. (2006) The process of establishing, implementing and maintaining a social support infant feeding programme. Public Health Nutr $\mathbf{9}$, 714-721.

31. Martins RK \& McNeil DW (2009) Review of motivational interviewing in promoting health behaviors. Clin Psychol Rev 29, 283-293.

32. Schwartz RP, Hamre R, Dietz WH et al. (2007) Office-based motivational interviewing to prevent childhood obesity: a feasibility study. Arch Pediatr Adolesc Med 161, 495-501. 